\title{
AÇÃO EMPREENDEDORA COMO UNIDADE DE ANÁLISE DO EMPREENDEDORISMO: PROPOSIÇÃO DE UM ESQUEMA DE ANÁLISE.
}

André Spuri Garcia ${ }^{1}$

${ }^{1}$ Universidade Federal de Lavras 


\section{AÇÃO EMPREENDEDORA COMO UNIDADE DE ANÁLISE DO EMPREENDEDORISMO: PROPOSIÇÃO DE UM ESQUEMA DE ANÁLISE.}

Resumo: O empreendedorismo é comumente definido como a capacidade de inovar e iniciar um novo negócio. Ao longo dos anos o termo ganhou notoriedade e amplitude acadêmica e prática. Entretanto, quanto as pesquisas acadêmicas que buscam discutir o seu conceito e definição, ainda há uma lacuna a ser superada. Apesar dos avanços observados no campo do empreendedorismo ao longo dos anos, o necessário aprofundamento teórico-metodológico proposto em vários trabalhos recentes ainda não foi atingido. Nesse sentido, este trabalho busca contribuir com uma categoria recente, porém com grande potencial para o campo do empreendedorismo, a saber, a ação empreendedora. O objetivo do trabalho consiste em propor um esquema teórico para auxiliar na realização de pesquisas empíricas sobre a temática. $\mathrm{O}$ esquema proposto apresenta o trajeto desde a oportunidade empreendedora até o resultado final de uma ação empreendedora. Essa ação empreendedora é entendida como uma ação social constituída de múltiplas ações.

Palavras-chave: Empreendedorismo; Ação Empreendedora; Oportunidade; Ação Social

\section{$1 \quad$ Introdução}

Há muitas definições para o termo empreendedorismo (BAGGIO, BAGGIO, 2014; GOMES; LIMA; CAPELLE, 2013; SANTIAGO, 2009; CAMARGO; CUNHA; BULGACOV, 2008). Apesar disso, o empreendedorismo é comumente definido como a capacidade de inovar, criar um novo produto ou processo e iniciar um novo negócio (KLEIN et al, 2010). Inicialmente voltado para o campo da economia e das organizações privadas, o empreendedorismo extrapolou fronteiras e hoje pode ser encontrado em diversos campos. Como resultado, o termo passou a ser utilizado pelas mais diversas áreas e nos mais diversos contextos. Empreendedorismo social (DEES, 2017), sustentável (DEAN, McMULLEN, 2007), institucional (GREENWOOD, SUDDABY, 2006), corporativo (BOAS; SANTOS, 2014), público (MACK; GREEN; VERDLITZ, 2008; KEARNEY; HISRICH; ROCHE, 2007), entre outros, são alguns exemplos de como o termo ganhou amplitude acadêmica ao longo dos anos.

Além da amplitude acadêmica, na prática o empreendedorismo tem sido estimulado e constitui-se objeto de políticas públicas. Estado e mercado buscam incentivar o empreendedorismo como forma de sobreviver ao ambiente complexo e dinâmico no qual as organizações estão inseridas, além de representar fonte de desenvolvimento econômico. Nas universidades o empreendedorismo consolida-se cada vez mais como disciplina obrigatória em cursos relacionados com Administração e Economia e como disciplina facultativa em outros cursos.

Entretanto, a importância prática e o estímulo conferido ao empreendedorismo não são acompanhados de forma proporcional por pesquisas acadêmicas que buscam discutir o seu conceito e definição (COSTA; BARROS; CARVALHO, 2011). Assim, o fenômeno vem se consolidando na prática, mas o conceito ainda é polissêmico e difuso. Além disso, grande parte das pesquisas relacionadas ao empreendedorismo são empíricas e partem de duas principais 
correntes teóricas já a muito consolidadas, a saber, a econômica e a comportamentalista (SANTIAGO, 2009; CAMARGO, CUNHA, BULGACOV, 2008). Entretanto, essas abordagens já foram criticadas (MARTES, 2010; GOMES, LIMA, CAPELLE, 2013) por seu individualismo metodológico, por considerarem que apenas alguns indivíduos privilegiados podem ser empreendedores e por não explicarem o processo empreendedor. Portanto, essas abordagens devem ser encaradas como introdutórias e o campo precisa avançar.

Porém, poucos são os estudos (BERGLUND, 2005; WATSON, 2013; SPEDALE, WATSON, 2014) que buscam discutir criticamente estas abordagens ou procuram abordagens e vertentes alternativas. Nesse contexto, Shepherd (2015) coloca que o campo do empreendedorismo deve ser empreendedor em suas pesquisas e ir além de comprovar, testar e analisar as proposições e pressupostos destas duas abordagens (BORBA, MARINHO, ALBERTON, 2018; SANTOS, MOREIRA, 2017). É preciso buscar alternativas teóricas para o campo do empreendedorismo, pois o foco quase exclusivo em estudos empíricos pode levar a naturalização do termo (GOMES; LIMA; CAPELLE, 2013). Para tanto, são necessários trabalhos que realizem discussões conceituais e o diálogo com outros campos de conhecimento, tais como a sociologia, antropologia, entre outras, é essencial - ressalta-se aqui que as próprias abordagens econômica e comportamental se fortaleceram a partir do diálogo com outros campos.

Nesse sentido, uma guinada teórica surgiu a partir do conceito de oportunidades empreendedoras (ALVAREZ; BARNEY, 2007; SHANE, VANKATARAMAN, 2000). A partir desse conceito, o empreendedorismo passar a ser definido como o processo de descoberta e exploração dessas oportunidades. Nessa concepção, a natureza dessas oportunidades e como os empreendedores as descobrem e exploram passam a ser centrais, trazendo um caráter processual e sociológico para o empreendedorismo. Kitching e Rouse (2016) reconhecem a importância do conceito de oportunidades empreendedoras, mas apontam que o campo do empreendedorismo deve observar outras unidades de análise. Para os autores, as oportunidades empreendedoras não ajudam a "explicar adequadamente as causas, processos e consequências da ação empreendedora" (KITCHING, ROUSE, 2016, p. 2). Dimov (2011) destaca que o conceito de oportunidade e seus desdobramentos deram vitalidade ao campo, mas o progresso ficou aquém das expectativas.

Portanto, apesar dos avanços observados no campo do empreendedorismo ao longo dos anos (SHEPHERD, 2015), o necessário aprofundamento teórico-metodológico é proposto em vários trabalhos recentes (TOWNSEND et al, 2018; SHEPHERD, 2015; SPEDALE; WATSON, 2014; WELTER, 2011). Shepherd (2015), por exemplo, reconhece que o campo do empreendedorismo alcançou legitimidade, contudo é preciso avançar. Nesse contexto, emergem discussões ainda incipientes sobre o conceito de ação empreendedora. Para alguns autores o empreendedorismo é ação e não existe empreendedorismo sem a ação do empreendedor (MCMULLEN; SHEPHERD, 2006; BERGLUND, 2005; WATSON. 2013; SPEDALE, WATSON, 2014). Enfatizar a ação permite deslocar o foco do indivíduo para o processo empreendedor e observar como as coisas acontecem. Permite ainda "o estabelecimento de uma nova episteme [...] uma ruptura com certas visões predominantes do empreendedorismo" (GOMES, LIMA, CAPELLE, 2013, p. 216).

Apesar do reconhecimento da ação empreendedora como fundamental para o empreendedorismo (SHEPPERD, 2015; KLEIN; 2008; McMULLEN, SHEPHERD, 2006; 
BERGLUND, 2005), ainda são poucos e recentes os estudos que discutiram esse conceito, principalmente na literatura nacional (GOMES, LIMA, CAPELLE, 2013). Diante do exposto, este artigo busca contribuir para o avanço teórico-metodológico do empreendedorismo ao estudar uma categoria ainda pouco estudada, mas com grande potencial para avançar as pesquisas do campo. $\mathrm{O}$ artigo tem como objetivo apresentar um esquema teórico para compreender o empreendedorismo a partir da ação empreendedora. Ele foi construído a partir da revisão de debates atuais no campo do empreendedorismo.

Além desta introdução, o trabalho está divido em mais quatro tópicos. O seguinte apresenta um referencial teórico sobre a evolução do campo do empreendedorismo até chegar ao conceito de ação empreendedora. Adiante, apresenta a teoria da ação empreendedora. $\mathrm{O}$ quarto tópico apresenta e explica o esquema teórico proposto. Por fim, são apontadas as conclusões finais e sugestões para pesquisas futuras.

\section{Empreendedorismo e sua evolução teórica: do indivíduo empreendedor à ação empreendedora}

O empreendedorismo é atemporal e existiu em todas as economias e sociedades (SHEPHERD, 2015). Entretanto, até o início do século XX o empreendedorismo foi um tema marginal dentro de campos consolidados como economia, sociologia, entre outros (LANDSTRÖM, HARIRCHI, 2018). Essa marginalização pode ser explicada pelo pouco interesse prático no empreendedorismo até então (LANDSTRÖM, HARIRCHI, 2018), pois o desenvolvimento e crescimento econômico eram explicados não por inovações, mas pela produção em massa e pelas grandes organizações. Ao longo dos anos, porém, algumas mudanças (globalização, desregulamentação, surgimento de instituições financeiras) trouxeram uma nova dinâmica econômica, questionando o papel das grandes corporações como principais responsáveis pelas mudanças econômicas. Essas mudanças fortaleceram o papel do empreendedorismo.

Atualmente, o empreendedorismo é um assunto de grande interesse público (STEVENSSON, JARILLO, 2007) e o campo se configura como um dos mais relevantes dentro das ciências sociais aplicadas (CHANDRA, 2018; WIKLUND et al, 2011). O número de publicações aumentou consideravelmente e surgiram ramificações e novas áreas de pesquisa. A partir disso, houve um desenvolvimento teórico (SHANE, VENKATARAMAN, 2000), conceitual e metodológico em relação ao empreendedorismo (DAVIDSSON, 2016), o que fortaleceu o campo. O surgimento e engajamento de novos pesquisadores, difusão de centros de pesquisa, periódicos e eventos especializados, além de disciplinas em universidades faz com que o campo do empreendedorismo seja consolidado e alcance legitimidade acadêmica (LANDSTRÖM; HARIRCHI, 2018; KURATKO, MORRIS, 2017; DAVIDSSON, 2016; SHEPHERD, 2015).

Entretanto, nem sempre foi assim. Em sua evolução, o campo do empreendedorismo por vezes se aproximou e se sobrepôs a outros campos consolidados como, por exemplo, pequenas empresas e gestão estratégica (DAVIDSSON, 2016). Essa sobreposição, por vezes, colocou em questão a importância conceitual do empreendedorismo enquanto um campo de pesquisa autônomo. Shane e Venkataraman (2000, p. 217) colocam que "para que um campo da ciência social tenha utilidade, ele deve ter uma estrutura conceitual que explique e preveja 
um conjunto de fenômenos empíricos não explicados ou previstos por estruturas conceituais já existentes em outros campos" e que o campo do empreendedorismo é utilizado para explicar uma variedade de eventos dispersos, muitas vezes não relacionados e explicados por outras estruturas conceituais existentes (DAVIDSSON, 2016; ZAHRA, DESS, 2001; BRUYAT, JULIEN, 2000; SHANE, VENKATARAMAN, 2000). Shane e Venkataraman (2000) sustentam que grande parte da literatura sobre empreendedorismo busca explicar diferenças relacionadas ao desempenho relativo de indivíduos e novas empresas. Entretanto, ressaltam que existem outras abordagens (gestão estratégica, por exemplo) que conseguem explicar e prever essas diferenças de maneira mais eficaz que o quadro teórico até então existente sobre empreendedorismo.

Além disso, não há uma definição do objeto de pesquisa do empreendedorismo (BRUYAT, JULIEN, 2001) e nem mesmo uma definição do que seja empreendedorismo, o que faz com que o campo seja disperso e dificulta a criação de um quadro conceitual (CLARK, HARRISON, 2018; BAGGIO, BAGGIO, 2014; GOMES; LIMA; CAPELLE, 2013; SANTIAGO, 2009; CAMARGO; CUNHA; BULGACOV, 2008; ZAHRA, DESS, 2001; SHANE, VENKATARAMAN, 2000). Nesse sentido, Costa, Barros e Carvalho (2011) apontam que o termo se constitui de um "significante vazio", expressão utilizada por Laclau e Mouffe para caracterizar expressões que podem assumir os mais diversos significados.

Apesar dos muitos significados e de não ter um paradigma dominante, para Klein et al (2010, p. 2) o empreendedorismo é comumente definido como "inovação, criatividade, o estabelecimento de novas organizações ou atividades, ou algum tipo de novidade". É o mecanismo por meio do qual as falhas e ineficiências de mercado são descobertas e atenuadas, proporcionando crescimento econômico, inovações e mudanças sociais (SHANE; VENKATARAMAN, 2000).

As raízes intelectuais do campo são os trabalhos de economistas como Cantillon, Smith, Knight, Say e Schumpeter (CHANDRA, 2018; BAGGIO, BAGGIO, 2014). Não há consenso sobre as diferentes abordagens dentro do campo do empreendedorismo. Diferentes autores dividem o empreendedorismo em diferentes abordagens (CLARK, HARRISON, 2018; CHANDRA, 2018; BAGGIO, BAGGIO, 2014; COSTA, BARROS, CARVALHO, 2011; SHANE, VENKATARAMAN, 2000). Por se tratar de um campo mesclado (GARTNER, 1990) e ainda em construção, todas as abordagens são reconhecidas e aceitas, pois tem como objetivo fazer avançar o estudo do empreendedorismo. Não há consenso também em como o campo deve se desenvolver, pois alguns autores preferem uma definição unificadora e estreita, enquanto outros acreditam em uma definição mais ampla.

Apesar de muitas abordagens e vertentes, as abordagens econômica e comportamental são mais frequentemente citadas (LANDSTRÖM; HARIRCHI, 2018; CHANDRA, 2018; CLARK, HARRISON, 2018; SHANE, VENKATARAMAN, 2000). Em termos cronológicos, essas abordagens foram as primeiras que se destacaram no campo do empreendedorismo, ou seja, são abordagens introdutórias em torno das quais o campo se desenvolveu (GOMES; LIMA; CAPELLE, 2013). Pelo olhar da economia, "o empreendedor [é considerado] o agente essencial do processo de desenvolvimento" (CAMARGO; CUNHA; BULGACOV, 2008, p. 113). Dessa forma, a abordagem econômica busca evidenciar os benefícios econômicos do fenômeno, ou seja, o quanto os empreendedores criam valor econômico (VAN PRAAG, VERSLOOL, 2007). O empreendedor é considerado central para a dinâmica econômica. A 
abordagem comportamental, por sua vez, busca identificar traços psicológicos e características que diferenciem os empreendedores (CHANDRA, 2018, CLARK, HARRISON, 2018).

O conceito de oportunidade empreendedora representa uma guinada teórica importante para o campo (KITCHING, ROUSE, 2016). A partir dele, o empreendedorismo pode ser definido como o estudo das fontes de oportunidades e os processos de descoberta, criação e exploração das mesmas (SHANE; VENKATARAMAN, 2000; SARASON, DEAN; DILLARD, 2006). Dessa forma, o empreendedorismo passou a ser visto por uma perspectiva mais processual, que não explicasse apenas quem é o empreendedor e o que ele faz, mas, principalmente, como ele faz (CHANDRA, 2018; CLARK, HARRISON, 2018; ALVAREZ, BARNEY, 2007, SHANE, VENKATARAMAN, 2000, VENKATARAMAN, 1997). O empreendedorismo passa a ser visto, então, como "o exame acadêmico de como, por quem e com quais efeitos as oportunidades para criar bens e serviços futuros são descobertas, avaliadas e exploradas" (SHANE, VENKATARAMAN, 2000, p. 218). Wiklund et al (2011) apontam que a guinada teórica foi fundamental para a dinamicidade e consolidação do campo, pois a partir dela o campo do empreendedorismo encontrou um objeto próprio de estudo e agora explica e prevê um conjunto de fenômenos não explicados por outros campos.

Entretanto, conforme Sarason, Dean e Dillard (2006), os trabalhos se concentram na natureza do empreendedor (foco das abordagens econômicas e comportamental) ou na natureza da oportunidade, mas desconsideram o processo empreendedor como um todo. Dimov (2011) afirma que ao mudar o foco do desempenho das organizações para as oportunidades empreendedoras, o campo do empreendedorismo passa a analisar apenas os estágios iniciais dos empreendimentos. Entretanto, segundo o autor, o progresso esperado do campo a partir dessa mudança de foco ficou aquém das expectativas.

A partir disso, alguns autores (SHEPHERD, 2015; SPEDALE, WATSON, 2014; WATSON, 2013; GOMES, LIMA, CAPELLE, 2013) propõem que a análise do empreendedorismo seja a partir de uma perspectiva mais sociológica, o que Klein (2008) chama de sociologia do empreendedorismo. Por essa perspectiva o empreendedorismo deixa de analisar aspectos relacionados unicamente ao indivíduo e as oportunidades e adotam um enfoque mais amplo. Nesse contexto, emerge o conceito de ação empreendedora. A ideia de ação empreendedora não tem como objetivo superar o que já foi feito, mas fornecer uma alternativa teórica para complementar o que já está posto.

\section{Empreendedorismo e ação empreendedora}

A ação empreendedora já é reconhecida como uma importante unidade de análise para o campo do empreendedorismo (SHEPPERD, 2015; KLEIN; 2008; McMULLEN, SHEPHERD, 2006; BERGLUND, 2005). Apesar disso, poucos e recentes são os estudos que discutem o conceito (GOMES, LIMA, CAPELLE, 2013).

Berglund (2005) enfatiza que a característica fundamental do empreendedorismo é ação. Para Spedale e Watson (2014), a ação empreendedora é um fenômeno social e "colocar a noção de ação empreendedora no centro dos esforços teóricos e empíricos é uma maneira valiosa de ir além de uma noção de contexto como distinta do empreendedor individual" (SPEADALE; WATSON, 2014, p. 763). Gomes, Lima e Capelle (2013) destacam que a noção de ação empreendedora é fundamental para a superação do individualismo metodológico e para a 
desconstrução do imaginário do empreendedor enquanto um mito, um indivíduo com características diferenciadas. Nas palavras dos autores, "A noção de ação empreendedora abre, portanto, a possibilidade de considerar que indivíduos comuns, homens ou mulheres, podem, individualmente ou em grupo, praticar uma ação empreendedora de caráter radical ou incremental" (GOMES, LIMA, CAPEELE, 2013, p. 215).

É importante destacar que a ação empreendedora é um fenômeno cotidiano e não está atrelada apenas às grandes inovações ou a abertura de novos negócios (SHEPHERD, 2015; WATSON, 2013). Watson (2013), por exemplo, aponta em seu texto que consegue observar atividades empreendedoras em vários aspectos do cotidiano. Isso permite uma ampliação do campo de estudo do empreendedorismo. Lindgren e Packendorf (2009) apontam que a ação empreendedora pode ser entendida como qualquer ato distinto daqueles já institucionalizados.

Chen et al (2018) destacam que a ação empreendedora é o que faz a conexão entre a intenção do indivíduo e a conclusão objetiva dessa intenção. Em termos de oportunidades, a ação empreendedora é uma resposta a um julgamento sobre uma possível oportunidade (McMULLEN, SHEPHERD, 2006), isto é, uma ação realizada quando se decide explorar uma oportunidade. Outros autores (KLEIN, 2008; LERNER, HUNT, DIMOV, 2018) colocam o empreendedorismo como um tipo particular de atividade humana.

as ações empreendedoras são aquelas que proporcionam a produção de inovações radicais ou não, mas, principalmente, incrementais, seja por meio do oferecimento de novos serviços/produtos, seja por meio da aquisição de novos recursos produtivos/gerenciais, isto é, por meio de mudanças administrativas ou de implantação de novos processos (GOMES, LIMA, CAPELLE, 2013, p. 215)

Spedale e Watson (2013) definem a ação empreendedora como "a realização de trocas aventureiras, criativas ou inovadoras (ou acordos) entre a empresa do ator empreendedor e outras partes com as quais a empresa comercializa." (SPEDALE; WATSON, 2013, p. 762). Essa ação ocorre na interação entre indivíduo e sociedade e surge das tensões entre lógicas institucionais e das tensões da orientação de vida dos indivíduos. A tensão entre lógicas institucionais surge das múltiplas ordens institucionais existentes (Estado, família, religião, entre outras). A tensão da orientação de vida está relacionada com os diferentes significados que os indivíduos atribuem aos fenômenos no decorrer da vida - existe um processo constante de busca de identidade que gera tensões e ressignificações ao longo da vida.

As definições apresentadas avançam ao reconhecer o empreendedorismo como um processo e como um fenômeno transitório, mas não indicam como ocorre a ação empreendedora. Para Watson (2013) e Shepherd (2015) mais que reconhecer a categoria ação empreendedora, é necessário pesquisar as múltiplas dimensões da atividade empreendedora, ou seja, buscar compreender como, de fato, se desenvolve essa ação. Diante disso, o tópico seguinte apresenta um esquema de análise para compreender o processo empreendedor a partir da ação empreendedora.

\section{Um caminho para a ação empreendedora}

O esquema (Figura 1) foi construído a partir de uma revisão bibliográfica não sistematizada. Foi inspirado principalmente, na agenda de pesquisa proposta no trabalho de 
Shepherd (2015), além de incluir outros debates (SPEDALE, WATSON, 2014; WATSON, 2013; GOMES, LIMA, CAPELLE, 2013; ALVAREZ, BARNEY, 2007; SHANE, VENKATARAMAN, 2000) encontrados na literatura, principalmente internacional.

Figura 1 - Modelo de análise do processo empreendedor a partir da ação empreendedora

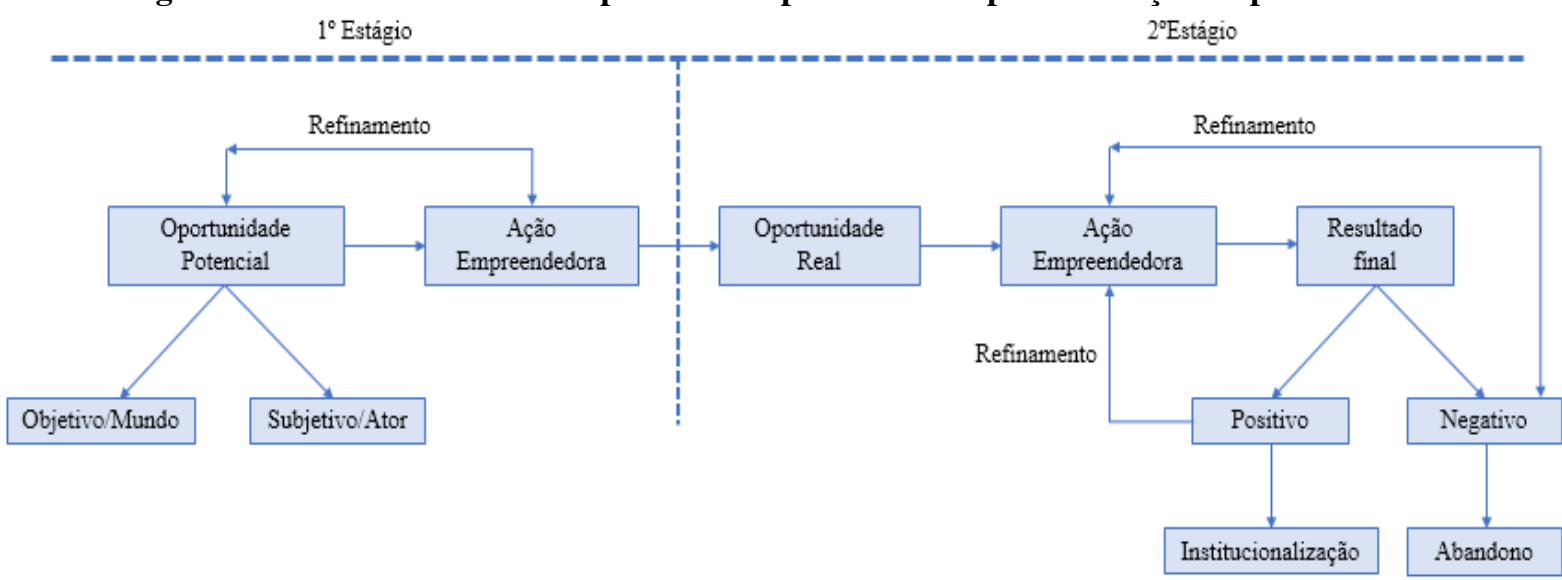

Fonte: Elaborado pelos autores

Nos subtópicos seguintes serão apresentadas as explicações do esquema proposto. Cada subtópico busca justificar e sustentar teoricamente o modelo proposto.

\section{a) Utilizar uma abordagem interativa de identificação e refinamento de oportunidades potenciais}

O empreendedorismo nasce a partir de uma oportunidade empreendedora. A discussão sobre essas oportunidades gira em torno de duas principais hipóteses (ALVAREZ; BARNEY, 2007): 1) essas oportunidades são objetivas, isto é, existem independente dos empreendedores; 2) ou são construídas pelos empreendedores. Este debate é relevante na medida em que essas duas vertentes implicam em diferentes modos de condução da ação empreendedora. No primeiro caso, os empreendedores realizam ações empreendedoras para explorar as oportunidades existentes, enquanto no segundo eles realizam ações empreendedoras para formar as oportunidades.

Em relação à teoria da descoberta, as oportunidades empreendedoras surgem de choques exógenos. Estes choques podem ser, por exemplo, mudanças na tecnologia, na preferência dos consumidores, mudanças demográficas e políticas (ALVAREZ, BARNEY, 2007). As oportunidades independem, portanto, das ações dos empreendedores. Nesse contexto, o papel do empreendedor consiste em realizar ações para descobrir e explorar essas oportunidades. Por outro lado, a teoria da criação considera que essas oportunidades são criadas, endogenamente, pelas "ações, reações e atuação de empreendedores que exploram maneiras de produzir novos produtos ou serviços" (ALVAREZ; BARNEY; 2007, p. 15).

Tanto a descoberta quanto a criação das oportunidades têm sido comumente explicadas a partir de diferenças individuais, mas os resultados não encontram respaldos empíricos significativos (SHEPHERD, 2015; ALVAREZ, BARNEY, 2007; BRUYAT, JULIEN, 2000; SHANE, VENKATARAMAN, 2000). Segundo Shepherd (2015), o que predomina nas 
pesquisas sobre oportunidades empreendedoras é a busca de características psicológicas e cognitivas que diferenciam os indivíduos em termos de formação de crença sobre uma oportunidade. Nesse sentido, o individualismo metodológico predomina e a sociedade tem apenas um papel de apoio - a assimetria de informações e os recursos para explorar uma oportunidade, por exemplo.

Para complementar a abordagem centrada no indivíduo, sem a intenção de superá-la, Shepherd (2015) propõe analisar uma oportunidade em termos de um processo de interação social. Para Shepherd (2015, p. 491), "uma oportunidade em potencial provavelmente será desencadeada pela experiência de um indivíduo no mundo e deve ser testada no contexto". Ser testada implica em receber feedbacks de diferentes atores (consumidores, fornecedores, pesquisadores, entre outros) sobre a veracidade dessa potencial oportunidade. A partir desses feedbacks o indivíduo pode refinar a oportunidade e testá-la novamente. Assim, no processo de interação o indivíduo é transformado e, consequentemente, a oportunidade potencial é refinada.

Portanto, quando se trata de compreender as dinâmicas de oportunidade de uma perspectiva mais baseada na interação, o desafio da pesquisa não é tanto determinar quando ou se a oportunidade em potencial está na "mente" ou no "mundo", mas para considerar os dois lados da interação; a mente e o mundo estão inextricavelmente ligados como uma "unidade funcional" através de um processo de ajuste mútuo (SHEPHERD et al, 2015, P. 492).

A partir do esquema proposto, uma oportunidade potencial possui aspectos objetivos e também subjetivos, ou seja, possui uma existência objetiva, mas precisa ser reconhecida pelo ator empreendedor. Em outras palavras, a oportunidade potencial pode ser entendida como a ideia inicial. A partir desse reconhecimento inicial o ator realizará uma ação empreendedora para refinar essa oportunidade e transformá-la em uma oportunidade real. Em termos metodológicos, essa oportunidade potencial e seu refinamento podem ser detalhados por meio de entrevistas, por exemplo.

\section{b) Entender a ação empreendedora como múltiplas ações}

Shepherd (2015) afirma que grande parte dos estudos buscam analisar e entender o resultado final de uma ação empreendedora, mas negligenciam as múltiplas ações envolvidas. Assim, a ação empreendedora pode ser melhor entendida como um processo dinâmico e iterativo a partir de uma oportunidade empreendedora. Por essa perspectiva, o processo empreendedor passa a ter as atividades de uma ação empreendedora como unidade de análise. Shepherd (2015, p. 494) denomina essas atividades de "micro-alicerces da ação empreendedora". A análise desses micro-alicerces faz com que a análise do processo empreendedor seja mais completa, aproximando o fenômeno do cotidiano e refletindo com maior exatidão a prática do empreendedorismo (SHEPHERD, 2015). Nesse mesmo sentido, sentido, Klein (2008) destaca a necessidade de reconhecer as múltiplas atividades relacionadas ao empreendedorismo.

Sem um entendimento dos micro-alicerces da ação empreendedora, o quadro do processo empreendedor é mais linear, grosseiro, e destacado da vida cotidiana, fornecendo pouca visão sobre a prática do empreendedorismo. Em vez disso, com 
ênfase nas atividades, a imagem do processo empreendedor é mais dinâmica, refinada e imersa. (SHEPHERD, 2015, p. 494)

Para Delmar e Shane (2004), a ação empreendedora é composta por uma série de ações. Os autores apontam três amplos conjuntos de atividades, a saber: atividades para construir a legitimidade da ação empreendedora; atividades relacionadas ao estabelecimento de relações com os diversos stakeholders; e atividades orientadas para o rearranjo e combinação de recursos. Não há consenso sobre a linearidade dessas ações ou se alguma deve preceder a outra. Entretanto, Delmar e Shane (2004) argumentam que as atividades relacionadas a legitimidade devem preceder as outras. Hannah e Freeman (1989) colocam o empreendedorismo como um processo constituído de vários subprocessos como, por exemplo, iniciação, mobilização de recursos, estabelecimento legal, organização social e atividades operacionais (HANNAH; FREEMAN, 1989).

Lichtenstein et al (2016) apontam que o processo empreendedor envolve atividades que são interdependentes e não lineares. Diante disso, é necessário buscar empiricamente padrões de atividades dentro do processo empreendedor. Gartner (1985) enfatiza que o processo empreendedor é complexo, multidimensional e evolui ao longo do tempo. Em seu framework para a criação de novos empreendimentos, Gartner (1985) apresenta como aspecto chave a análise das diversas ações realizadas para iniciar um novo empreendimento.

Portanto, a ideia de empreendedorismo como múltiplas ações foi reforçada recentemente no trabalho de Shepherd (2015), mas já existia em trabalhos anteriores. A discussão dessas múltiplas ações, entretanto, não avançou. Uma hipótese para isso é a força que outras unidades de análise ganharam dentro do campo do empreendedorismo como, por exemplo, as oportunidades empreendedoras e os traços comportamentais/psicológicos dos indivíduos empreendedores. Dessa forma, argumentamos que trabalhos empíricos devem elencar as múltiplas atividades que constituem um processo empreendedor.

Essa ação empreendedora e suas múltiplas atividades aparecem nos dois estágios do esquema. No primeiro estágio as múltiplas atividades são fundamentais para o refinamento da oportunidade potencial. A partir de uma oportunidade potencial o indivíduo (ou um grupo de indivíduos) realiza um conjunto de atividades para refinar essa oportunidade. Essas atividades podem incluir, por exemplo, pesquisas e conversas formais e informais sobre uma determinada ideia. No segundo estágio, já com a oportunidade real, outras atividades serão realizadas. Essas atividades provavelmente terão um caráter mais operacional como, por exemplo, mobilização de recursos, inclusive humanos, estabelecimento legal e atividades operacionais propriamente ditas (produção, vendas, prestação de serviços, etc.).

Em termos metodológicos, uma possibilidade para pesquisas empíricas consiste em elencar todas as atividades de um processo empreendedor. Essa coleta de dados pode ser feita por meio de entrevistas e observações, por exemplo. Shepherd (2015) sugere também a etnografia. A partir desses dados o pesquisador pode agrupar as atividades em categorias distintas ou seguir modelos pré-estabelecidos como os apresentados nos trabalhos de Gartner (1985) e Delmar e Shane (2004), por exemplo.

c) Ação empreendedora enquanto um fenômeno coletivo 
Com o desenvolvimento do campo, alguns autores começaram a analisar o empreendedorismo enquanto um fenômeno coletivo (BERNIER, 2014; TONELLI, BRITO, ZAMBALDE, 2011; BURRESS, COOK, 2009; WEST, 2007; ULHØI, 2005). Dessa forma, a atividade empreendedora pode ser vista como uma ação social coletiva, pois envolve vínculos com outros atores, interação com o contexto social e institucional, conceituação conjunta de oportunidades a partir de um processo interativo (SHEPERD, 2015; BURRESS, COOK, 2009). Entender o empreendedorismo enquanto fenômeno coletivo significa, portanto, reconhecer que existem múltiplos atores implícitos em uma atividade empreendedora. O coletivo aqui não está relacionado ao resultado da ação empreendedora, ou seja, não se trata de empreendedorismo social em que os resultados são coletivos (MAIR, MARTI, 2006). A ação empreendedora pode ser entendida como coletiva qualquer que seja o resultado dessa ação - a abertura de um novo negócio ou de uma organização filantrópica envolvem, ambas, relacionamentos sociais (SHEPHERD, 2015; BURRESS, COOK, 2009).

Burress e Cook (2009) colocam que o próprio Shumpeter, ainda que de forma incipiente, destacava o empreendedorismo como uma ação coletiva. Entretanto, evitou usar o termo empreendedorismo coletivo por receio, pois poderia ser mal interpretado e confundido com empreendedorismo social ou alguma conotação de cunho socialista (BURRESS, COOK, 2009). Adiante, Bouchikhi (1993) já destacava que o resultado do processo empreendedor é emergente de uma interação complexa entre o empreendedor, o meio ambiente e outros atores envolvidos (BOUCHIKHI, 1993). Em outras palavras, o empreendedorismo é resultado de uma ação coletiva. Para Burress e Cook (2009), o empreendedorismo é coletivo por natureza.

Também buscando contribuir conceitualmente com o campo do empreendedorismo, Tonelli, Brito e Zambalde (2011) e Korsgaard (2011) destacam o caráter coletivo da ação empreendedora. As ações e iniciativas empreendedoras devem ser entendidas "como resultantes de translações, as quais envolvem [...] agências distribuídas e tipos distintos de atores (humanos e não humanos)" (TONELLI, BRITO, ZAMBALDE, 2011, p. 595). Todos os elementos envoltos nessa ação são atuantes.

Dessa forma, além de elencar as múltiplas ações que constituem a ação empreendedora, uma pesquisa empírica deve elencar também quais os atores estavam envolvidos nessas atividades e qual a importância ou não desses atores para essas atividades - tanto no primeiro quanto no segundo estágio do esquema. Conforme destacado por Tonelli, Brito e Zambalde (2011), os atores não-humanos também são importantes para a análise, pois podem desempenhar papel importante nessas atividades. A coleta de dados relacionadas a esses atores pode ser feita por meio de entrevistas e também por meio de observações.

\section{d) Utilizar uma abordagem contextual para o empreendedorismo}

Para Klein (2008), ações empreendedoras ocorrem o tempo todo e, como qualquer ação, fazem parte do cotidiano. Klein et al (2010) observam o empreendedorismo "como uma função que pode ser executada por uma variedade de indivíduos sob circunstâncias variadas" (KLEIN et al, 2010, p. 2). Essa premissa afasta a ideia de que apenas alguns indivíduos são capazes de se envolver em ações empreendedoras. Para Shane e Venkataraman (2000), o comportamento empreendedor é transitório. Portanto, é simplório afirmar que um determinado grupo de pessoas 
possui características próprias que fazem delas empreendedoras, independente do contexto no qual estão inseridas.

A partir dessa perspectiva, a atividade empreendedora pode ocorrer em qualquer lugar e a qualquer momento. Isso reforça, portanto, a abordagem contextual defendida por Welter (2011). Portanto, "o empreendedorismo só é inteligível ao analisar o contexto coletivo maior no qual [...]se desdobra.” (BURRESS, COOK, 2009, p. 9).

Assim, reconhecer o ambiente externo é fundamental para entender a ação empreendedora. Segundo Welter (2011), o mesmo ambiente que fornece oportunidades empreendedoras estabelece limites para sua exploração. Para Yessoufou, Blok e Omta (2017), o empreendedorismo só pode ser entendido pela interação social entre os indivíduos e o contexto social e cultural por trás dessas interações. Para tanto, os autores defendem que o empreendedorismo deve ser entendido "como um fenômeno em evolução dinâmica que ganha significado e forma a partir de relações complexas em seu contexto situado, geradas pela interdependência de agência, estruturas e ações empreendedoras" (YESSOUFOU, BLOK, OMTA, 2017, p. 6). Nesse mesmo sentido, Kitching e Rouse (2016) colocam que não existe ação livre de contexto. A partir disso, conceituam a ação empreendedora como um processo "[...] emergente da interação entre empreendedores e seus contextos" (KITCHING, ROUSE, 2016). Concordando com o exposto por Shepherd (2015), Welter (2011) coloca que a literatura sobre empreendedorismo superestima a influência de fatores internos e negligencia os aspectos externos.

Corroborando com o esquema proposto, enfatizar o contexto faz com que o caráter social do empreendedorismo seja colocado em discussão. Dessa forma, "conectar ações a contextos de organização permite que os pesquisadores evitem o individualismo metodológico anteriormente priorizado no campo [...] para reconhecer o "nexo" ou inter-relação de múltiplos fatores que moldam as construções empreendedoras" (FLETCHER, 2011, p. 68).

Dessa forma, a observação do contexto se torna importante para amparar a ideia de empreendedorismo como uma ação social. O contexto pode auxiliar a compreensão de quem são os múltiplos atores humanos e não-humanos que influenciam direta ou indiretamente uma ação empreendedora. O desafio metodológico aqui é delimitar um contexto específico para análise empírica do fenômeno.

\section{e) O resultado da ação empreendedora e seus desdobramentos}

Conforme o esquema proposto, a ação empreendedora - suas múltiplas atividades constituintes - culminam em um resultado. Medir o resultado do empreendedorismo é um desafio metodológico. Argumentamos que o resultado de uma ação empreendedora pode ser analisado por diferentes dimensões, a saber: econômica, social, ambiental, cultural e institucional, por exemplo. Dessa forma, pesquisas empíricas podem, inicialmente, vincular a análise desses resultados a partir da intenção e dos objetivos do ator empreendedor. Em outras palavras, é preciso saber qual o resultado esperado de uma ação para que seja possível analisar seu resultado. Um empreendedorismo privado, por exemplo, pode ter o resultado econômico como primeira dimensão de análise, mas as demais dimensões também devem ser analisadas.

Nesse sentido, a incorporação do contexto proposta anteriormente se torna ainda mais importante se observarmos a ampliação do empreendedorismo para outros tipos de 
organizações. Durante muito tempo o empreendedorismo ficou restrito às organizações privadas. Inicialmente voltado para o campo da economia, administração e das organizações privadas, a contribuição do empreendedorismo era observada por meio do desenvolvimento econômico e financeiro dos territórios e pela geração de riqueza, enquanto questões sociais e ambientais eram evitadas (SARANGO-LALANGUI; SANTOS; HORMIGA, 2018). Entretanto, com o desenvolvimento do campo e a ampliação do conceito, o empreendedorismo passa a ser compreendido não apenas como propulsor do desenvolvimento econômico, mas também como instrumento para gerar benefícios sociais e ambientais (MAIR, MARTI, 2006; MUÑOZ, COHEN, 2018).

Em outras palavras, o empreendedorismo deixa de ser analisado apenas pelo valor econômico gerado. Portanto, essa ampliação do conceito permite a aplicação do empreendedorismo a outros campos organizacionais e reforça a necessidade de observar seu resultado para além da dimensão econômica. Nesse contexto, o termo pode ser utilizado pelas mais diversas áreas e nos mais diversos contextos, o que culmina em derivações como, por exemplo, empreendedorismo sustentável (DEAN, McMULLEN, 2007), institucional (GREENWOOD, SUDDABY, 2006), corporativo (BOAS; SANTOS, 2014), entre outros.

Esse resultado pode ser classificado pelo empreendedor como positivo ou negativo. Importante destacar que essa classificação é subjetiva e está relacionada com o resultado inicialmente esperado pelo empreendedor. A partir dessa avaliação inicial o empreendedor pode: a) considerar o resultado positivo, mas não o suficiente e refinar sua ação empreendedora para ajustar seu resultado; b) considerar o resultado negativo e refinar sua ação empreendedora para ajustar seu resultado; c) considerar o resultado negativo e abandonar essa ação empreendedora, descartando a oportunidade - apesar de não ser dominante nas pesquisas, o insucesso é um possível resultado de ações empreendedoras (SINGH; CORNER; PAVLOVICH, 2007); d) considerar o resultado positivo o suficiente e institucionalizar essa ação. Por ação institucionalizada estamos considerando que as ações seguintes serão guiadas por "conteúdos cognitivamente internalizados" (GRIGOLETO, 2018, p. 92).

Em pesquisas empíricas, o pesquisador pode fazer uma análise dos resultados diferente do empreendedor, pois pode analisar outras dimensões e, além disso, não tem a mesma intenção/expectativa inicial dele. Dessa forma, em termos metodológicos é importante indagar ao empreendedor quais as expectativas inicias da ação empreendedora.

\section{Considerações finais}

Conforme demonstrado, o campo do empreendedorismo precisa avançar e ser empreendedor em suas pesquisas (SHEPHERD, 2015) se quiser manter sua legitimidade acadêmica. Nesse sentido, este trabalho foca em uma categoria recente, porém com grande potencial explicativo, a saber, a ação empreendedora. $\mathrm{O}$ objetivo, portanto, foi propor um esquema teórico para entender o processo empreendedor a partir da ação empreendedora.

O esquema proposto parte da oportunidade empreendedora. Baseado em alguns trabalhos (SHEPHERD, 2015; SPEDALE; WATSON, 2014; SHANE, VENKATARAMAN, 2000), partimos de uma perspectiva dinâmica para a construção de uma oportunidade real. Nessa perspectiva, uma oportunidade potencial é transformada por meio da ação empreendedora. Em outras palavras, o ator empreendedor percebe uma oportunidade potencial e por meio de suas ações - inerentemente sociais - a transforma em uma oportunidade real. A 
partir dessa oportunidade real o empreendedor passa a desenvolver uma nova ação empreendedora para alcançar um determinado resultado, que será julgado pelo próprio empreendedor. A partir disso ele pode refinar sua ação para ajustar o resultado alcançado, considerar o resultado satisfatório o suficiente ou abandonar a oportunidade empreendedora.

Este estudo não pretende esgotar todas as possibilidades de análise do processo empreendedor. Como qualquer proposição, espera-se que este trabalho esteja sujeito a avaliação crítica e que seja julgado e testado diante da literatura existente. Como colocam Lindgren e Packendorff (2009, p. 29) "Qualquer construtor(es) do campo operará sob as mesmas condições de qualquer empreendedor da vida real - assumir o risco de se desviar das práticas atuais também significa assumir a tarefa de convencer o contexto das vantagens da novidade". A intenção é romper com a inércia das pesquisas no campo do empreendedorismo, principalmente na literatura nacional. Dessa forma, a partir deste trabalho novos modelos e insights podem surgir e fazer avançar o campo.

Como sugestão de pesquisa propomos, inicialmente, uma discussão mais profunda das categorias oportunidade empreendedora e ação empreendedora. Conforme ressaltado, essas categorias são recentes e podem enriquecer a literatura nacional tanto em termos teóricos quanto em pesquisas empíricas. Adiante, sugerimos a construção de mais esquemas como estes e os seus respectivos testes em pesquisas empíricas.

\section{Referências}

ALVAREZ, Sharon A.; BARNEY, Jay B. Discovery and creation: Alternative theories of entrepreneurial action. Strategicentrepreneurshipjournal, v. 1, n. 1-2, p. 11-26, 2007.

BAGGIO, Adelar Francisco; BAGGIO, Daniel Knebel. Empreendedorismo: Conceitos e definições. Revista de empreendedorismo, inovação e tecnologia, v. 1, n. 1, p. 25-38, 2014. BERGLUND, H. Toward a theory of entrepreneurial action: exploring risk, opportunity and self in technology entrepreneurship. 2005. PhD Thesis (Departament of Technology Management and Economics) - Chalmers University of Technology, Gothenburg, Sweden, 2005.

BERNIER, Luc. Public enterprises as policy instruments: the importance of public entrepreneurship. Journal of Economic Policy Reform, v. 17, n. 3, p. 253-266, 2014.

BOAS, Eduardo Pinto Vilas; DOS SANTOS, Silvio Aparecido. Empreendedorismo corporativo: estudo de casos múltiplos sobre as práticas promotoras em empresas atuantes no Brasil. Revista de Administração, v. 49, n. 2, p. 399-414, 2014.

BORBA, João Francisco; MARINHO, Sidnei Vieira; ALBERTON, Anete. Perfil Empreendedor: O Caso da Mula sem Cabeça. Revista de Empreendedorismo e Gestão de Pequenas Empresas, v. 7, n. 1, p. 226-242, 2018.

BOUCHIKHI, Hamid. A constructivist framework for understanding entrepreneurship performance. OrganizationStudies, v. 14, n. 4, p. 549-570, 1993.

BRUYAT, Chirstian; JULIEN, Pierre-André. Defining the field of research in entrepreneurship. Journal of business venturing, v. 16, n. 2, p. 165-180, 2001.

BURRESS, Molly J.; COOK, Michael Lee. A primer on collective entrepreneurship: a preliminary taxonomy. 2009 
CAMARGO, Denise de; CUNHA, Sieglind; BULGACOV, Yára Lúcia. A psicologia de McClelland e a economia de Schumpeter no campo do empreendedorismo. RDE-Revista de Desenvolvimento Econômico, v. 10, n. 17, 2008.

CHANDRA, Yanto. Mapping the evolution of entrepreneurship as a field of research (1990 2013): A scientometric analysis. PloS one, v. 13, n. 1, p. e0190228, 2018.

CHEN, H. Shawna et al. Perceived psychological distance, construal processes, and abstractness of entrepreneurial action. Journal of Business Venturing, v. 33, n. 3, p. 296-314, 2018.

CLARK, Catherine M.; HARRISON, Christian. Entrepreneurship: an assimilated multiperspective review. JournalofSmall Business \&Entrepreneurship, v. 31, n. 1, p. 43-71, 2018. COSTA, Alessandra Mello da; BARROS, Denise Franca; CARVALHO, José LuisFelicio. The historical dimension of the discourses concerning the entrepreneur and entrepreneurship. Revista de AdministraçãoContemporânea, v. 15, n. 2, p. 179-197, 2011.

DAVIDSSON, Per. The field of entrepreneurship research: Some significant developments. In: Contemporary Entrepreneurship. Springer, Cham, 2016. p. 17-28.

DEAN, Thomas J.; MCMULLEN, Jeffery S. Toward a theory of sustainable entrepreneurship: Reducing environmental degradation through entrepreneurial action. Journal of business venturing, v. 22, n. 1, p. 50-76, 2007.

DEES, J. Gregory. 1 The Meaning of Social Entrepreneurship. In: Case studies in social entrepreneurship and sustainability. Routledge, 2017. p. 34-42.

DELMAR, Frédéric; SHANE, Scott. Legitimating first: Organizing activities and the survival of new ventures. Journal of business venturing, v. 19, n. 3, p. 385-410, 2004.

DIMOV, Dimo. Grappling with the unbearable elusiveness of entrepreneurial opportunities. EntrepreneurshipTheoryandPractice, v. 35, n. 1, p. 57-81, 2011.

FLETCHER, Denise E. A curiosity for contexts: Entrepreneurship, enactive research and autoethnography. Entrepreneurship and Regional Development, v. 23, n. 1-2, p. 65-76, 2011.

GARTNER, William B. A conceptual framework for describing the phenomenon of new venture creation. Academy of management review, v. 10, n. 4, p. 696-706, 1985.

GARTNER, William B. What are we talking about when we talk about entrepreneurship?. Journal of Business venturing, v. 5, n. 1, p. 15-28, 1990.

GOMES, Almiralva; LIMA, Juvêncio; CAPPELLE, Mônica. Do empreendedorismo à noção de ações empreendedoras: reflexões teóricas. Revista Alcance, v. 20, n. 2, 2013.

GREENWOOD, Royston; SUDDABY, Roy. Institutional entrepreneurship in mature fields: The big five accounting firms. Academy of Management journal, v. 49, n. 1, p. 27-48, 2006. GRIGOLETTO, Fábio. O bairro Guapiruvu como lugar-organização: uma abordagem institucional do organizar. 2018. Tese de Doutorado.

HANNAN, Michael T.; FREEMAN, John. Structural inertia and organizational change. American sociological review, p. 149-164, 1984.

KEARNEY, Claudine; HISRICH, Robert D.; ROCHE, Frank. Public and private sector entrepreneurship: similarities, differences or a combination?. Journal of Small Business and Enterprise Development, v. 16, n. 1, p. 26-46, 2009. 
KITCHING, John; ROUSE, Julia. Opportunity or dead end? Rethinking the study of entrepreneurial action without a concept of opportunity. International Small Business Journal, v. 35, n. 5, p. 558-577, 2017.

KLEIN, Peter G. et al. Toward a theory of public entrepreneurship. European management review, v. 7, n. 1, p. 1-15, 2010.

KLEIN, Peter G. Opportunity discovery, entrepreneurial action, and economic organization. Strategic Entrepreneurship Journal, v. 2, n. 3, p. 175-190, 2008.

KORSGAARD, Steffen. Entrepreneurship as translation: Understanding entrepreneurial opportunities through actor-network theory. Entrepreneurship \& Regional Development, v. 23, n. 7-8, p. 661-680, 2011.

KURATKO, Donald F.; MORRIS, Michael H. Examining the future trajectory of entrepreneurship. Journal of Small Business Management, v. 56, n. 1, p. 11-23, 2017.

LANDSTRÖM, Hans; HARIRCHI, Gouya. The social structure of entrepreneurship as a scientific field. Research Policy, v. 47, n. 3, p. 650-662, 2018.

LERNER, Daniel A.; HUNT, Richard A.; DIMOV, Dimo. Action! Moving beyond the intendedly-rational logics of entrepreneurship. Journal of Business Venturing, v. 33, n. 1, p. 52-69, 2018.

LICHTENSTEIN, Benyamin B. et al. Complexity dynamics of nascent entrepreneurship. Journal of Business Venturing, v. 22, n. 2, p. 236-261, 2007.

LINDGREN, Monica; PACKENDORFF, Johann. Social constructionism and entrepreneurship: Basic assumptions and consequences for theory and research. International Journal of Entrepreneurial Behavior \& Research, v. 15, n. 1, p. 25-47, 2009.

MACK, W. R.; GREEN, Deanna; VEDLITZ, Arnold. Innovation and implementation in the public sector: An examination of public entrepreneurship. Review of policy research, v. 25, n. 3, p. 233-252, 2008.

MAIR, Johanna; MARTI, Ignasi. Social entrepreneurship research: A source of explanation, prediction, and delight. Journal of world business, v. 41, n. 1, p. 36-44, 2006.

MARTES. A. C. B. Weber e Schumpeter A ação econômico do empreendedor. Revista de Economia Política,. v 30, n 2, 2010. 254-270p.

MCMULLEN, Jeffery S.; SHEPHERD, Dean A. Entrepreneurial action and the role of uncertainty in the theory of the entrepreneur. Academyof Management review, v. 31, n. 1, p. 132-152, 2006.

MUÑOZ, Pablo; COHEN, Boyd. Sustainable entrepreneurship research: Taking stock and looking ahead. Business Strategy and the Environment, v. 27, n. 3, p. 300-322, 2018.

SANTIAGO, E. G. Vertentes teóricas sobre empreendedorismo em Shumpeter, Weber e McClelland: novas referências para a sociologia do trabalho. Revista de Ciências Sociais, v. 40, n. 2, p. 87-103, 2009.

SANTOS, M. F; MOREIRA, O. P. Desenvolvimento Econômico E Social Na Comunidade Local Impulsionados Pelo Empreendedorismo. Caderno de Administração, v. 16, n. 2, p. 6776, 2017.

SARANGO-LALANGUI, Paul; SANTOS, Jane; HORMIGA, Esther. The development of sustainable entrepreneurship research field. Sustainability, v. 10, n. 6, p. 2005, 2018. 
SARASON, Yolanda; DEAN, Tom; DILLARD, Jesse F. Entrepreneurship as the nexus of individual and opportunity: A structuration view. Journalof business venturing, v. 21, n. 3, p. 286-305, 2006.

SHANE, Scott; VENKATARAMAN, Sankaran. The promise of entrepreneurship as a field of research. Academy of management review, v. 25, n. 1, p. 217-226, 2000.

SHEPHERD, Dean A. Party On! A call for entrepreneurship research that is more interactive, activity based, cognitively hot, compassionate, and prosocial. Journal of Business Venturing, v. 30, n. 4, p. 489-507, 2015.

SINGH, Smita; CORNER, Patricia; PAVLOVICH, Kathryn. Coping with entrepreneurial failure. Journal of Management \& Organization, v. 13, n. 4, p. 331-344, 2007.

SPEDALE, Simona; WATSON, Tony J. The emergence of entrepreneurial action: At the crossroads between institutional logics and individual life-orientation. International Small Business Journal, v. 32, n. 7, p. 759-776, 2014.

STEVENSON, Howard H.; JARILLO, J. Carlos. A paradigm of entrepreneurship: Entrepreneurial management. In: Entrepreneurship. Springer, Berlin, Heidelberg, 2007. p. 155-170.

TONELLI, Dany Flávio; DE BRITO, Mozar José; ZAMBALDE, André Luiz. Empreendedorismo na ótica da teoria ator-rede: explorando alternativa às perspectivas subjetivista e objetivista. Cadernos EBAPE. BR, p. 586-603, 2011.

TOWNSEND, David M. et al. Uncertainty, knowledge problems, and entrepreneurial action. Academy of Management Annals, v. 12, n. 2, p. 659-687, 2018.

ULHØI, John P. The social dimensions of entrepreneurship. Technovation, v. 25, n. 8, p. 939946, 2005.

VAN PRAAG, C. Mirjam; VERSLOOT, Peter H. Whatisthevalueofentrepreneurship? A review of recent research. Small business economics, v. 29, n. 4, p. 351-382, 2007.

VENKATARAMAN, Sankaran. The distinctive domain of entrepreneurship research. Advances in entrepreneurship, firm emergence and growth, v. 3, n. 1, p. 119-138, 1997.

WATSON, Tony J. Entrepreneurship in action: bringing together the individual, organizational and institutional dimensions of entrepreneurial action. Entrepreneurship \& Regional Development, v. 25, n. 5-6, p. 404-422, 2013.

WELTER, Friederike. Contextualizing entrepreneurship-conceptual challenges and ways forward. Entrepreneurship theory and Practice, v. 35, n. 1, p. 165-184, 2011.

WEST, G. Page. Collective cognition: When entrepreneurial teams, not individuals, make decisions. Entrepreneurship Theory and Practice, v. 31, n. 1, p. 77-102, 2007.

WIKLUND, Johan et al. The future of entrepreneurship research. Entrepreneurship Theory and Practice, v. 35, n. 1, p. 1-9, 2011.

YESSOUFOU, Ahoudou W.; BLOK, Vincent; OMTA, S. W. F. The process of entrepreneurial action at the base of the pyramid in developing countries: a case of vegetable farmers in Benin. Entrepreneurship \& Regional Development, v. 30, n. 1-2, p. 1-28, 2018.

ZAHRA, Shaker; DESS, Gregory G. Entrepreneurship as a field of research: Encouraging dialogue and debate. Academy of management Review, v. 26, n. 1, p. 8-10, 2001. 